\title{
NEWSLETTER vol. 1, no. 4
}

Table 1. A resource comparison* of the *SELECT IF and MULT RESPONSE techniques for filtered marginals.

\begin{tabular}{lll}
\hline RESOURCE & *SELECT IF & MULT RESPONSE \\
\hline NUMBER OF JOBS & 2 & 1 \\
KBYT-SEC & 21,016 & 24,957 \\
ELAP-KBS & 180,493 & 73,752 \\
READER EXCP** & 93 & 31 \\
PRINTER EXCP & 14,630 & 3,844 \\
PUBLIC DISK EXCP & 10,476 & 360 \\
PRIVATE DISK EXCP & 10 & 5 \\
TAPE EXCP & 72 & 36 \\
TAPE MOUNTS & 2 & 1 \\
COST & $\$ 31.70$ & $\$ 13.39$ \\
ELAPSED TIME & $13.48 \mathrm{~min}$. & $6.23 \mathrm{~min}$. \\
\hline
\end{tabular}

*Comparisons were performed on the University of Connecticut's Research Computer Center IBM 360/65 - IBM 370/155 systems running under OS and shared spool HASP. Local costs may vary from installation to installation.

**Each EXCP represents the "Execution of a channel program" and indicates the movement of one block of data.

The MULT RESPONSE procedure can further be extended to filtered bivariate tables by including a second BY statement on the TABLES card. This technique is not illustrated due to space limitations. Readers are referred to their local installations for further documentation of SPSS Version 7.0.

\section{DISCUSSION PAPER/richard c. roistacher}

The following article describes the work of Richard C. Roistacher and Barbara Noble at the Center for Advanced Computation at the University of Illinois. They are involved in the development of guidelines for the descriptive materials which accompany a data file.

\author{
A Source Documentation Style Manual \\ by \\ Richard Roistacher \\ Center for Advanced Computation \\ University of Illinois \\ Urbana, Illinois
}

Barbara Noble and Richard Roistacher of the University of Illinois' Center for Advanced Computation are currently developing a style manual for the documentation of machine readable data. The manual, which is being developed as part of a project funded by the U.S. Department of Justice's Law Enforcement Assistance Administration, is presently available in draft form. The manual, conforming to the 
naming conventions of the U.S. Government's Federal Information Processing Standards, is titled LEAA Research Support Center Machine Readable Source Documentation System: User's Guide.

The style manual is designed to serve the needs of data producers, archivists, and users. It was developed from several current series of documentation, as we11 as from the LEAA project's experience in archiving a number of large criminal justice data files.

The manual gives an annotated example of each major section of the source documentation for a machine readable data file. The manual's major sections describe the cover, abstract, introduction, codebook, and appendices of source documentation. The section on the cover gives advice on the titling, authorship, and citation of files and documentation. The manual's chapters on the abstract and introduction sections gives a form for abstracts, and gives advice on how to describe the file's collection, methodological, and processing history. The chapter on the codebook section gives formats for data item blocks for several types of data. The chapter on appendices gives formats for listings of known errors, definitions of terms, dictionary descriptions, description of data shipments, and extended code listings.

At present, the examples in the manual cover only rectangular files of survey data. Additions to the manual will cover the documentation of hierarchical and other complex files, time series, network data, and generalized arrays.

The documentation manual is designed to be independent of any particular manual or computer based system for producing documentation. However, the LEAA project at the Center for Advanced Computation has developed a computer system for producing machine readable source documentation conforming to the manual. The system merges the information in an OSIRIS III data dictionary file into a file of documentation text. The documentation text is processed with the University of British Columbia's FMT document processing program to yield a finished codebook, which can be printed or copied to tape. The system will automatically reformat and reorder the documentation to match a data file which has been subsetted, reordered, or merged. New page numbers, tables of contents, cross references, and indices are generated by the FORMAT program without any intervention by the user. A later version of the system, which runs on IBM hardware, will extract format information from SPSS system files.

This winter, Noble and Roistacher will hold a conference on the documentation of machine readable data. One of the major purposes of the conference will be to expand and refine the current draft of the documentation style manual.

The authors would welcome advice and comments from data producers, archivists, and users. Copies of the current draft are available to interested people, and any comments would be welcome. Copies are available from Barbara B. Noble or Richard C. Roistacher, Center for Advanced Computation, University of Illinois, Urbana, IL 61801.

[Editor's Note: The meeting was held on 0ctober 27 and 28, 1977 in Boston. Revisions to the Manual were recommended. A full report will appear in the next issues of IASSIST as Roistacher and Noble further refine the Manual.] 
igssist NEWSLETTER vol. 1, no. 4 DATA ORGANIZATION REGISTRY FORM
june 1977

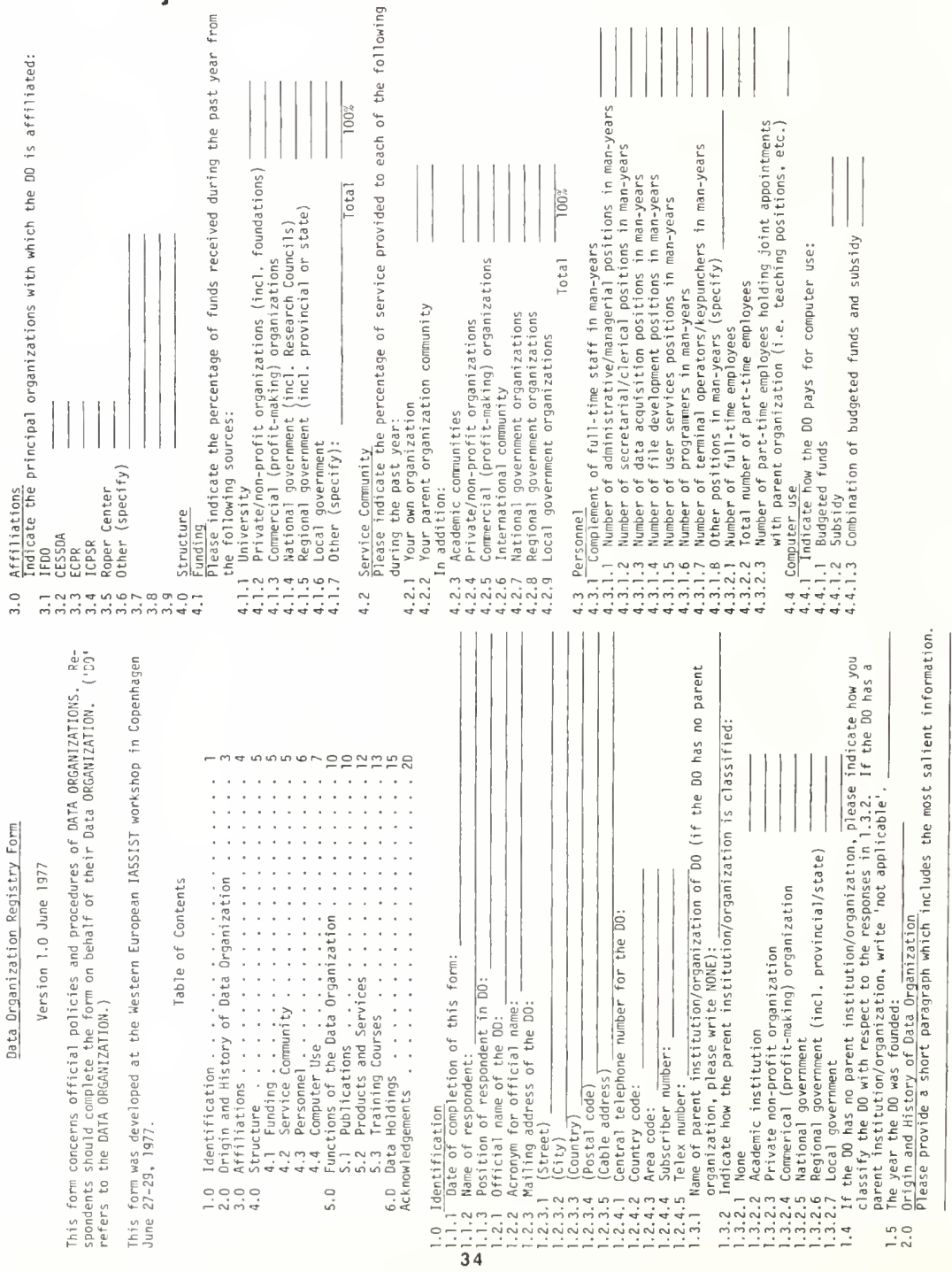


I. Ssist NEWSLETTER vol. 1, no. 4
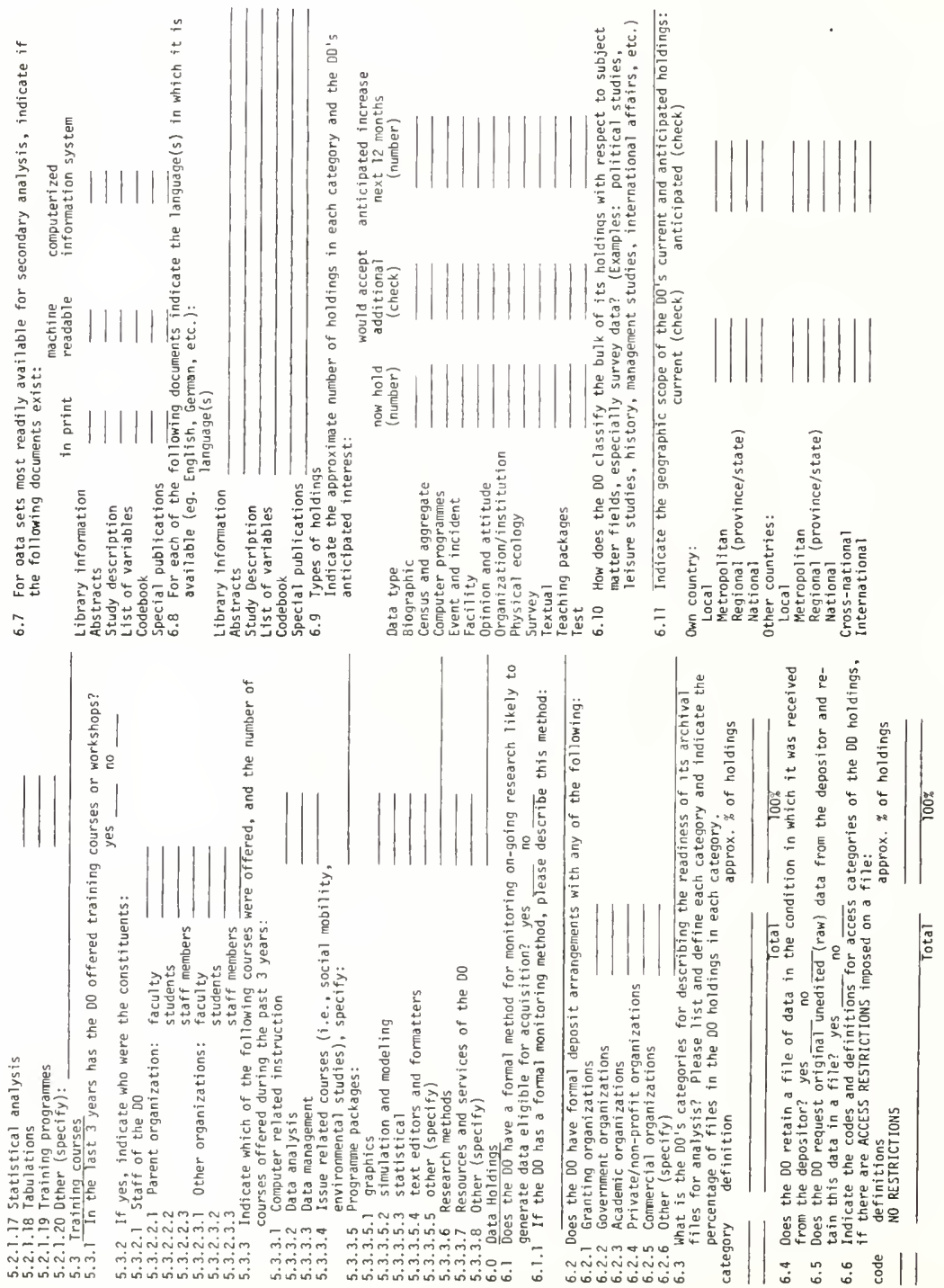